This is a pre-copy-editing, author-produced PDF of an article accepted for publication in the British Journal of Anaesthesia following peer review. The definitive publisher-authenticated version [ $\mathrm{Br} \mathrm{J}$ Anaes 2007;98(3):347-52] is available online at: http://bja.oxfordjournals.org/content/vol98/issue3/index.dtl

\title{
INTERDISCIPLINARY COMMUNICATION IN THE INTENSIVE CARE UNIT
}

Tom W Reader MA*, Rhona Flin PhD*, Kathryn Mearns PhD*, Brian $\mathrm{H}$ Cuthbertson** MD FRCA,

*School of Psychology, University of Aberdeen, Kings College, Aberdeen, Scotland, $\mathrm{UK}, \mathrm{AB} 242 \mathrm{UB}$

**Health Services Research Unit, University of Aberdeen, Foresterhill, Aberdeen, Scotland, UK, AB25 2ZD.

Short title: Interdisciplinary communication in the ICU

Name of institution where worked performed- University of Aberdeen, Aberdeen Scotland, UK.

Address for correspondence: Mr Tom Reader, School of Psychology, University of Aberdeen, Kings College, Aberdeen, Scotland, UK, AB24 2UB

Phone +44 1224 273212; Fax +44 1224 273211; E-mail tom.reader@abdn.ac.uk

Financial support: This work was supported by a $\mathrm{PhD}$ studentship from the College of Life Sciences and Medicines, University of Aberdeen.

Reprints: Will not be offered.

Conflicts of interest: None.

Financial interests: None of the authors have any financial interests relating to this work. 
SUMMARY (Word count- 239)

Background: Patient safety research has shown poor communication amongst ICU nurses and doctors to be a common causal factor underlying critical incidents in intensive care. The current study examines whether ICU doctors and nurses have a shared perception of interdisciplinary communication in the UK intensive care unit.

Methods: Cross-sectional survey of ICU nurses and doctors in four UK hospitals using a previously established measure of ICU interdisciplinary collaboration.

Results: A sample of 48 doctors and 136 nurses (47\% response rate) from 4 ICUs responded to the survey. Nurses and doctors were found to have differing perceptions of interdisciplinary communication, with nurses reporting lower levels of communication openness between nurses and doctors. Compared to senior doctors, trainee doctors also reported lower levels of communication openness between doctors. Furthermore, a regression path analysis revealed that communication openness amongst ICU team members predicted the degree to which individuals reported understanding their patient care goals $\left({ }^{\text {adj }} R^{2}=0.17\right)$. It also showed that perceptions of the quality of unit leadership predicted open communication.

Conclusions: Members of ICU teams have divergent perceptions of their communication with one another. Communication openness amongst team members is also associated with the degree to which they understand patient care goals. In order to ensure team members in the ICU feel that they can communicate openly, it is necessary to create a safe atmosphere where team members feel they can communicate openly without fear of reprisal or embarrassment.

Key words: Teamwork; Interdisciplinary communication; patient safety; leadership; patient care planning 


\section{Introduction}

Effective team communication and coordination are recognised as being crucial for improving quality and safety in acute medical settings such as the intensive care unit (ICU) ${ }^{1,2}$. Research studying communication failures in medical teams has indicated the influence that hierarchical and social factors have upon the behaviours of junior medical staff. Communication failures can emerge from junior team members being reluctant to communicate openly with senior team members because of a fear of either appearing incompetent, or of being rejected, embarrassed or reprimanded ${ }^{3}$. Attitudinal research in the US has indicated that ICU team members have divergent perceptions of their communication behaviours, with more nurses than doctors reporting difficulties in speaking-up about problems with patient care, and fewer nurses reporting that teamwork between nurses and doctors is well coordinated ${ }^{4,5}$. Not only do such factors increase the likelihood of medical errors occurring ${ }^{6}$, the degree to which communication in the ICU is open may also influence the degree to which patient care duties are understood. Through the use of communication interventions that promote teamwork across role boundaries (e.g. ICU daily goals sheets), making communication more inclusive and explicit has been shown to increase team members' understanding of patient care plans in the $\operatorname{ICU}{ }^{7,8}$.

The current study examined whether nurses and doctors working in UK ICUs have differing perceptions of their interdisciplinary communication, with the prediction being that trainee team members (e.g. trainee doctors) will have less positive perceptions than senior team members (e.g. senior doctors). Furthermore, this study examined whether individuals who report higher levels of open communication within the ICU also report having a better understanding of their patient care goals, and 
whether the leadership of senior ICU staff is important in fostering a perception of communication openness. 


\section{Method}

\section{Participants}

The study was a cross-sectional survey carried out in 4 Scottish ICUs during July to December 2005. The ICUs were closed units (where patients are admitted only after approval, and are cared for full-time, by intensivists and their teams). Doctors and nurses agreed to be surveyed with regards to interdisciplinary collaboration in their unit (table 1). Ethical approval was acquired from relevant review bodies. At each location, a senior nurse distributed questionnaires to the nursing staff, and a senior doctor distributed questionnaires to the medical staff. In total, 400 questionnaires were distributed over the course of a month. The questionnaires were anonymous, with participants returning the completed questionnaires in freepost envelopes to the research team.

\section{INSERT TABLE 1 HERE}

\section{Materials}

The survey measure was adapted from the 'Interdisciplinary Collaboration' questionnaire developed by Shortell et al. ${ }^{9}$, which contains a range of questions on ICU communication between interdisciplinary groups (i.e. between nurses and doctors), and within interdisciplinary groups (i.e. between doctors). The tool is psychometrically well validated ${ }^{10}$, and has been used previously to assess ICU teamwork in the US ${ }^{11-13}$. Twelve scales regarding communication and leadership were taken from the survey instrument (table 2), and terminology was adapted for the UK with the help of an ICU consultant and an ICU senior nurse. One additional 5item scale was specially developed for the survey. This scale measured how often 
ICU staff feel they understand the patient care plans and potential safety risks for the patients under their care. The scale was based on questions used in studies examining the understanding of patient care duties ${ }^{7,8}$, was developed with ICU staff, and was piloted successfully in the first surveyed unit. Biodata such as age and gender were not requested in order to ensure anonymity and increase participation in the study.

\section{INSERT TABLE 2 HERE}

\section{Statistical analysis}

Prior to any analysis, the internal reliability of the questionnaire scales was assessed by calculating Cronbach's alpha scores, (these indicate the consistency of responses to the items that comprise a questionnaire scale). A Cronbach's alpha score of above 0.7 indicates acceptable consistency ${ }^{14}$. All but three scales showed acceptable reliability ( $\alpha>=0.7$ ). Two scales (accuracy between shifts, and accuracy within shifts) showed reliability slightly below the acceptance criteria $(\alpha>0.6)$. Although not ideal, it was consistent with the original questionnaire validation criteria, and thus the scales were retained. However, the 'shift communication between groups' scale had unacceptably low reliability $(\alpha=0.47)$ and was excluded from further analysis. The distribution of respondent scores was found to be normal for all scales except 'Understanding patient care goals', which had a negatively skewed distribution. In order to normalise the scale, a 'log transformation' was performed. Multivariate analysis of variance (MANOVA) was conducted to examine whether there was an overall effect for differences in responses to perceptions of communication between i) doctors and nurses, and between ii) senior doctors and trainee doctors, and senior nurses and trainee nurses. Post-hoc tests were then conducted to examine the specific differences 
between responses to the questionnaire scales, with Hochberg's GT2 test procedure being used to test for comparisons where there was a large difference in the sample size. Additionally, the proportions of staff within each group that reported very positive perceptions (between $4 \& 5$ ) on each scale, (and thus may perceive a reduced need for improvements in teamwork) were calculated along with Cohen's d effect sizes ${ }^{15}$, which are used to examine the strength of an observed effect and are reported as Pearson's correlation coefficients.

A multiple regression was conducted to examine whether open communication in the ICU predicts respondent reports of understanding patient care goals. Lastly, a mediation analysis using regression path analysis (which is used to examine the mechanisms through which one variable affects another, whilst taking into the account the variance explained by a third variable) ${ }^{16}$ examined whether unit leadership was also important in predicting understanding patient care goals whilst taking into account the variance explained by reports of open communication in the ICU. Data were analysed using SPSS for Windows version 14. 


\section{Results}

A total of 184 questionnaires were returned (47\% response rate): 48 questionnaires (26\% of the sample) were received from doctors (17 senior doctors, 13 specialist registrars, 15 senior house officers, and 3 unknown) and 136 (74\% of the sample) were received from nurses (24 senior nurses and 112 staff nurses). The mean response scores showed a similar pattern of results to the original US scale ${ }^{9}$, with the majority of respondents reporting positive responses to the questionnaire scales (table 2). The MANOVA showed a significant effect $(\lambda=.750, \mathrm{~F}(14,164)=3.59, \mathrm{p}<0.001)$ in terms of the groups taking part in the study reporting different perceptions of communication. Furthermore, the post-hoc analysis revealed a number of significant differences between professional groups (Table 3). Doctors reported significantly higher levels of communication openness when compared to nurses $(\mathrm{p}<0.01)$. Specifically, most senior doctors $(82 \%)$, and over half of trainee doctors $(60 \%)$, reported very high levels of communication openness between nurses and doctors, as compared to around a third of nurses (37\%). Senior doctors also reported significantly higher levels of communication openness between doctors $(p<0.05)$, with $88 \%$ of senior doctors reporting very positive perceptions, as compared to $53 \%$ of trainee doctors. For communication accuracy, senior doctors reported less positive perceptions of communication accuracy between themselves and both nurses $(p<$ $0.01)$ and trainee doctors $(\mathrm{p}<0.05)$.

\section{INSERT TABLE 3}


The multiple regression analysis revealed communication openness between and within groups to be significant predictors of understanding patient care goals, accounting for approximately $17 \%$ of the variance $\left({ }^{\mathrm{adj}} R^{2}=0.17, p<0.001\right)$. A regression path analysis was conducted to examine the mediational model hypothesising that perceptions of unit leadership predict reports of open communication in the ICU, which in turn influences the degree to which staff understand patient care goals. Due to the similarity between the two communication openness and leadership scales, and also due to regression path analysis only being able to examine the relationship between three variables (a predictor, a mediator, and a dependent variable), it was decided to amalgamate both communication openness scales into one 'open communication in the ICU' scale, and also to amalgamate both leadership scales into one 'unit leadership' scale. The regression path analysis showed the data to be consistent with the hypothesised mediational model due to it meeting the required mediation assumptions as described by Baron and Kenny ${ }^{16}$. Figure 1 describes the path analysis and shows the regression output and the Sobel test statistic. This was conducted to assess the significance of mediational effects, and showed communication openness to account for $52 \%$ of the variance explained by the relationship between unit leadership and understanding patient care goals, thus supporting the mediational model.

\section{INSERT FIGURE 1 HERE}




\section{Discussion}

The results indicate that doctors and nurses in the UK intensive care environment have differing perceptions of multidisciplinary communication in the ICU. Nurses reported less communication openness between the two groups, whilst senior doctors had particularly positive perceptions. Senior doctors and trainee doctors also show a distinction in their perceptions of communication openness between doctors, with senior doctors reporting more positive perceptions. However, senior doctors reported less favourable responses than trainee staff in terms of their perceptions of communication accuracy in the ICU. Factors that are likely to produce such differing perspectives on communication include hierarchical factors, gender, differing patient care responsibilities, differing perceptions of requisite communication standards, and differences in the training methods of nurses and doctors ${ }^{4}$. The regression analysis found open communication amongst team members in the ICU to be a predictor of the degree to which individuals report understanding patient care goals. Although only a moderate predictor (other factors such as medical training, unit culture, and years of ICU experience might also be strong predictors), communication openness may facilitate the understanding of patient care goals through junior team members feeling more able to ask senior team members for confirmation of patient care duties, to discuss patient care plans issues they do not understand, and to become more involved in developing patient care goals. Lastly, the finding that unit leadership is an important determinant of open communication is consistent with leadership research in other domains ${ }^{17}$.

The importance of communication openness in medical teams has been documented previously. In particular, creating a safe atmosphere where team members feel they 
can speak up should they have any safety concerns or issues with the quality of care provided to patients is essential ${ }^{18,19}$. This atmosphere can be created through team leadership that advocates a less steep hierarchy: that shows a willingness to listen to the concerns and ideas of junior team members: that recognises human limitations, and that clearly states expected team interaction patterns ${ }^{19-21}$. Also important for developing open communication amongst teams is the implementation of protocols (e.g. communication checklists) that support communication across hierarchical boundaries ${ }^{7,22}$, and team-based training that encourages assertiveness, interdisciplinary communication, and a shared perception of teamwork ${ }^{18,23}$.

\section{Study limitations}

There are a number of limitations to this study. Firstly, although the return rate is not as high as in some other healthcare surveys ${ }^{4}$, it is comparable to other teamwork research conducted in other domains ${ }^{24}$. Secondly, the measures used in the survey were all self-report measures, which renders the study susceptible to common method bias and social desirability biases. In particular, the patient care goals scale showed a skew towards respondents reporting that they always understand their patient care duties; in future this could be more objectively assessed through observational techniques. The unequal sample sizes reported in the study are also a potential confounding factor, with a small sample of senior doctors compared to nurses and trainee doctors. Also, the lack of demographic data did not allow comparisons between female and male ICU team members, which has previously been proposed to be a factor in the differing perceptions of nurses and doctors ${ }^{4}$. Future research may wish to focus further on senior doctors in order to provide data on a larger sample, as well as exploring the factors (e.g. leadership) underlying divergence in perceptions of 
teamwork and open communication. A new study is currently underway with a psychologist observing communication during morning rounds and ICU round members' recording their personal judgements of patient state for each consultation.

\section{Conclusions}

Patient safety research has shown communication failures to be causal factors in many ICU critical incidents. This study indicated that different professional groups of ICU team members have divergent perceptions of communication in the ICU. Communication openness was also found to be associated with the degree to which team members report understanding patient care goals. In order to ensure team members in the ICU feel that they can communicate openly, it is necessary to create a safe atmosphere where team members feel they can speak up openly without fear of reprisal or embarrassment if they have any safety concerns or issues with the quality of care provided to patients. 


\section{Acknowledgements}

We acknowledge the support of the ICU staff who participated in the study at the following hospitals; Aberdeen Royal Infirmary, the Western General Edinburgh, the Royal Infirmary of Edinburgh, and Stirling Royal Infirmary. We would also like to thank the ICU senior nurses and doctors who helped to facilitate the survey. 


\section{References}

1. Baggs JG, Schmitt MH, Mushlin AI, Mitchell PH, Eldrege DH, Oakes D: Association between nurse-physician collaboration and patient outcomes in three intensive care units. Crit Care Med 1999; 27: 1991-8

2. Reader T, Flin R, Lauche K, Cuthbertson B: Non-technical skills in the Intensive Care Unit. Br J Anaesth 2006; 96: 551-9

3. Edmondson A: Psychological safety and learning behaviour in work teams. Adm Sci Q. 1999; 44: 350-83

4. Thomas EJ, Sexton JB, Helmreich RL: Discrepant attitudes about teamwork among critical care nurses and physicians. Crit Care Med 2003; 31: 956-9

5. Miller PA: Nurse-physician collaboration in an intensive care unit. American J Crit Care 2001; 10: $341-50$

6. Sutcliffe KM, Lewton E, Rosenthal MM: Communication failures: An incidious contributor to medical mishaps. Acad Med 2004; 79: 186-94

7. Pronovost PJ, Berenholtz SM, Dorman T, Lipsett PA, Simmonds T, Haraden C: Improving communications in the ICU using daily goals. J Crit Care 2003; 18: $71-5$

8. Dodek PM, Raboud J: Explicit approach to rounds in an ICU improves communication and satisfaction of providers. Intensive Care Med 2003; 29: $1584-8$

9. Shortell SM, Zimmerman JE, Rousseau DM, et al: The performance of intensive care units: Does good management make a difference? Med Care 1994; 32: $508-25$

10. Render ML, Hirschhorn L: An irreplaceable safety culture. Crit Care Clin 2005; 21: $31-41$ 
11. Boyle D, Kochinda C: Enhancing collaborative communication of nurse and physician leadership in two intensive care units. $J$ Nurs Adm 2004; 34: 60-70

12. Baker GR, King H, Macdonald JL, Horbar JD: Using organizational assessment surveys for improvement in neonatal intensive care. Pediatrics. 2003; 111: $419-25$

13. Zimmerman JE, Shortell SM, Rousseau DM, et al: Improving intensive care: observations based on organizational case studies in nine intensive care units: A prospective, multicenter study. Crit Care Med 1993; 21: 1443-51

14. Field A: Discovering Statistics Using SPSS. $2^{\text {nd }}$ Edn. London: SAGE Publications, 2005

15. Cohen J: Statistical power analysis for the behavioral sciences Hillsdale, NJ: Lawrence Erlbaum Associates, 1988

16. Baron R, Kenny D: The moderator-mediator variable distinction in social psychological research: Conceptual, strategic, and statistical considerations. J Pers Soc Psychol 1986; 51: 1173-82

17. Flin R, Yule S: Leadership for safety: industrial experience. Qual Saf Health Care 2004; 13 (suppl II): 45-51

18. Leonard M, Graham S, Bonacum D: The human factor: the critical importance of effective teamwork and communication in providing safe care. Qual Saf Health Care 2004; 13: 85-90

19. Burke CS, Salas E, Wilson-Donnelly K, Priest H: How to turn a team of experts into an expert medical team: guidance from the aviation and military communities. Qual Saf Health Care 2004; 13:96-1104

20. Sexton JB, Thomas EJ, Helmreich RL: Error, stress and teamwork in medicine and aviation: cross sectional surveys. BMJ 2000; 320:745-749 
21. Edmondson AC: Speaking up in the operating room: How team leaders promote learning in interdisciplinary action teams. J Manag Stud 2003; 40:1419-1452

22. Lingard LA, Espin SL, Rubin HR, et al: Getting teams to talk: development and pilot implementation of a checklist to promote interprofessional communication in the OR. Qual Saf Health Care 2005; 14:340-346

23. Undre S, Sevdalis N, Healey A, Darzi S, Vincent C: Teamwork in the operating theatre: cohesion or confusion? J Eval Clin Pract 2006; 12:182-189

24. Griffin M, Patterson M, West M. Job satisfaction and teamwork: The role of supervisor support. J Org Behav 2001; 22: 537-550 
Table 1. ICU admission and outcome data for the four surveyed ICUs

\begin{tabular}{l|c}
\hline & Median (range) \\
\hline ICU admission p.a. & $629(215-1123)$ \\
\hline ICU bed number & $10.5(4-14)$ \\
\hline Occupancy & $78.5(70-85)$ \\
\hline Operative admissions & $43 \%$ \\
\hline Male / female (\%) & $56 / 44$ \\
\hline Median age (years) & 59 \\
\hline Median ICU stay (days) & 2 \\
\hline Mean ICU stay (days) & 4.8 \\
\hline ICU mortality (\%) & 21.3 \\
\hline Hospital mortality (\%) & 29 \\
\hline
\end{tabular}


Table 2. Descriptions, means and positive response percentages for the survey scales used in the current study

\begin{tabular}{|c|c|c|c|}
\hline Survey scale & Scale description & $\begin{array}{c}\text { Mean } \\
\text { scores* }\end{array}$ & $\begin{array}{l}\text { \% Positive } \\
\text { response }\end{array}$ \\
\hline $\begin{array}{l}\text { Communication openness } \\
\text { between nurses and doctors }\end{array}$ & $\begin{array}{l}\text { Items measure the extent to which ICU nurses and doctors can } \\
\text { speak openly with one another without fear of negative } \\
\text { repercussions or misunderstanding [4-items] }\end{array}$ & 3.60 & $77 \%$ \\
\hline $\begin{array}{l}\text { Communication openness } \\
\text { within groups }\end{array}$ & $\begin{array}{l}\text { Items measure the extent to which ICU team members within } \\
\text { a group (e.g. between doctors) can speak openly with one } \\
\text { another without fear of negative repercussions or } \\
\text { misunderstanding [4-items] }\end{array}$ & 3.92 & $85 \%$ \\
\hline $\begin{array}{l}\text { Communication accuracy } \\
\text { between nurses and doctors }\end{array}$ & $\begin{array}{l}\text { Items measure the degree to which nurses and doctors believe } \\
\text { that information conveyed to one another is accurate [3-items] }\end{array}$ & 3.55 & $70 \%$ \\
\hline $\begin{array}{l}\text { Communication accuracy } \\
\text { within groups }\end{array}$ & $\begin{array}{l}\text { Items measure the degree to which ICU team members within } \\
\text { a group (e.g. between senior and trainee nurses) believe } \\
\text { information conveyed to one another is accurate [ } 3 \text {-items] }\end{array}$ & 3.37 & $60 \%$ \\
\hline $\begin{array}{l}\text { Shift communication between } \\
\text { groups }\end{array}$ & $\begin{array}{l}\text { Items measure the extent to ICU nurses and doctors feel } \\
\text { between shift communication with one another is effective [2- } \\
\text { items] }\end{array}$ & 3.43 & $61 \%$ \\
\hline $\begin{array}{l}\text { Shift communication within } \\
\text { groups }\end{array}$ & $\begin{array}{l}\text { Items measure the extent to which ICU team members within } \\
\text { a group (e.g. doctors) feel between shift communication with } \\
\text { one another is effective [2-items] }\end{array}$ & 3.42 & $60 \%$ \\
\hline $\begin{array}{l}\text { Unit communication } \\
\text { timeliness }\end{array}$ & $\begin{array}{l}\text { Items measure the degree to which information about patient } \\
\text { care is promptly relayed to relevant caregivers [5-items] }\end{array}$ & 3.72 & $83 \%$ \\
\hline $\begin{array}{l}\text { Satisfaction with nurse and } \\
\text { doctor communication }\end{array}$ & $\begin{array}{l}\text { Overall satisfaction with the quality of nurse and doctor } \\
\text { communication [1-item] }\end{array}$ & 3.70 & $72 \%$ \\
\hline $\begin{array}{l}\text { Satisfaction with } \\
\text { communication within groups }\end{array}$ & $\begin{array}{l}\text { Overall satisfaction with the quality of between group (e.g. } \\
\text { between nurses) communication [1-item] }\end{array}$ & 3.74 & $72 \%$ \\
\hline Doctor leadership & $\begin{array}{l}\text { Items measure the degree to which staff rate the effectiveness } \\
\text { (e.g. for emphasizing standards and making clear what is } \\
\text { expected of ICU staff) of senior doctor leadership [4-items] }\end{array}$ & 3.38 & $63 \%$ \\
\hline Nursing leadership & $\begin{array}{l}\text { Items measure the degree to which staff rate the effectiveness } \\
\text { (e.g. for emphasizing standards and making clear what is } \\
\text { expected of ICU staff) of senior nurse leadership [4-items] }\end{array}$ & 3.65 & $76 \%$ \\
\hline Perceived unit effectiveness & $\begin{array}{l}\text { Items measure perceptions of overall unit effectiveness for } \\
\text { meeting patient care treatment goals, responding to emergency } \\
\text { situations, and functioning well as a team [6-items] }\end{array}$ & 3.88 & $93 \%$ \\
\hline $\begin{array}{l}\text { Understanding patient care } \\
\text { goals }\end{array}$ & $\begin{array}{l}\text { Items measure the extent to which ICU doctors and nurses } \\
\text { understand the care duties (e.g. understanding short and long- } \\
\text { term patient care plans, awareness of safety risks, and an } \\
\text { understanding of what needs to be done for the patient to be } \\
\text { discharged from the ICU) for patients under their care. [5- } \\
\text { items] }\end{array}$ & 4.05 & N/A \\
\hline
\end{tabular}

\footnotetext{
* All scales are measured on a Likert scale of 1 - strongly disagree; 2 - disagree; 3 - neither agree nor disagree; 4 - agree; 5 strongly agree; except the understanding patient care goals which is measured on a scale of 1 - never; 2 - seldom; 3 sometimes; 4 - often; 5 - always

** A positive response is where respondents have given a mean answer of greater than 3 on the questionnaire scales
} 
Table 3. Significant differences in responses to the survey scales between groups of ICU staff

\begin{tabular}{|c|c|c|c|c|c|}
\hline Survey scale & $\begin{array}{r}\text { Comparison } \\
\text { groups } \\
\end{array}$ & $\begin{array}{l}\text { Means } \\
\text { and SD }\end{array}$ & $\begin{array}{c}\mathbf{p} \\
\text { value }\end{array}$ & $\begin{array}{l}\text { \% of responses } \\
\text { between } 4 \text { \& } 5\end{array}$ & $\begin{array}{l}\text { Effect } \\
\text { size } \mathbf{r}^{*}\end{array}$ \\
\hline \multicolumn{6}{|c|}{ Differences in perceptions between doctors and nurses for: } \\
\hline $\begin{array}{l}\text { Communication openness } \\
\text { between nurses and doctors }\end{array}$ & $\begin{array}{l}\text { Doctors } \\
\text { Nurses }\end{array}$ & $\begin{array}{l}3.86(.68) \\
3.51(.7)\end{array}$ & $<0.01$ & $\begin{array}{l}68 \% \\
37 \%\end{array}$ & .26 \\
\hline $\begin{array}{l}\text { Communication accuracy } \\
\text { between nurses and doctors }\end{array}$ & $\begin{array}{l}\text { Doctors } \\
\text { Nurses }\end{array}$ & $\begin{array}{l}3.32(.73) \\
3.63(.58)\end{array}$ & $<0.01$ & $\begin{array}{l}30 \% \\
46 \%\end{array}$ & .22 \\
\hline Doctor leadership & $\begin{array}{l}\text { Doctors } \\
\text { Nurses }\end{array}$ & $\begin{array}{l}3.53(.65) \\
3.32(.59)\end{array}$ & $<0.05$ & $\begin{array}{l}36 \% \\
18 \%\end{array}$ & .17 \\
\hline \multicolumn{6}{|c|}{ Differences in perceptions between senior doctors and trainee doctors for: } \\
\hline $\begin{array}{l}\text { Communication openness } \\
\text { between nurses and doctors }\end{array}$ & $\begin{array}{l}\text { Senior doctors } \\
\text { Trainee doctors }\end{array}$ & $\begin{array}{l}4.20(.69) \\
3.70(.57)\end{array}$ & $<0.05$ & $\begin{array}{l}82 \% \\
60 \%\end{array}$ & .36 \\
\hline $\begin{array}{l}\text { Communication openness } \\
\text { between doctors }\end{array}$ & $\begin{array}{l}\text { Senior doctors } \\
\text { Trainee doctors }\end{array}$ & $\begin{array}{l}4.27(.73) \\
3.59(.81)\end{array}$ & $<0.05$ & $\begin{array}{l}88 \% \\
53 \%\end{array}$ & .40 \\
\hline $\begin{array}{l}\text { Communication accuracy } \\
\text { between doctors }\end{array}$ & $\begin{array}{l}\text { Senior doctors } \\
\text { Trainee doctors }\end{array}$ & $\begin{array}{l}2.97(.7) \\
3.52(.83)\end{array}$ & $<0.05$ & $\begin{array}{l}15 \% \\
46 \%\end{array}$ & .34 \\
\hline Doctor leadership & $\begin{array}{l}\text { Senior doctors } \\
\text { Trainee doctors }\end{array}$ & $\begin{array}{l}3.88(.58) \\
3.39(.62)\end{array}$ & $<0.05$ & $\begin{array}{l}54 \% \\
29 \%\end{array}$ & .37 \\
\hline Understanding patient care goals & $\begin{array}{l}\text { Senior doctors } \\
\text { Trainee doctors }\end{array}$ & $\begin{array}{l}4.55(.6) \\
3.85(.5)\end{array}$ & $<0.01$ & $\begin{array}{l}77 \% \\
53 \%\end{array}$ & .53 \\
\hline \multicolumn{6}{|c|}{ Differences in perceptions between senior nurses and trainee nurses for: } \\
\hline Understanding patient care goals & $\begin{array}{l}\text { Senior nurses } \\
\text { Trainee nurses }\end{array}$ & $\begin{array}{l}4.35(.6) \\
3.99(.61)\end{array}$ & $<0.05$ & $\begin{array}{l}56 \% \\
70 \%\end{array}$ & .28 \\
\hline
\end{tabular}

* An effect size score of $\mathrm{r}=.1$ indicates a small effect, $\mathrm{r}=.3$ indicates a medium effect, and $\mathrm{r}=.5$ indicates a large effect ${ }^{15}$. 
Figure 1. Regression path analysis ${ }^{16}$ showing open communication to mediate the relationship between unit leadership and understanding patient care goals, with unit leadership being a predictor of open communication in the ICU, and open communication in the ICU being a predictor of understanding patient care goals.

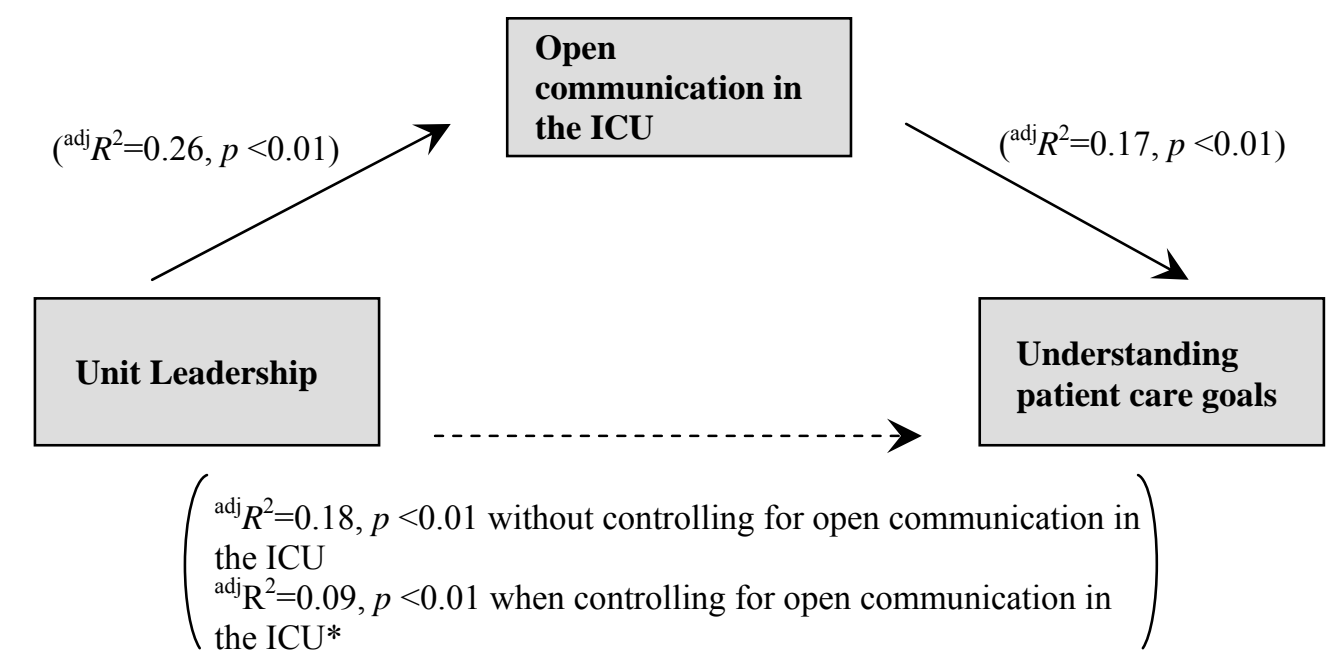

* the Sobel test statistic shows open communication to be a significant partial mediator of the relationship between unit leadership and understanding patient care goals $(\mathrm{p}<0.001)$, with it accounting for approximately $52 \%$ of the variance between the two variables 